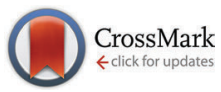

Cite this: Phys. Chem. Chem. Phys., $2016,18,21629$

Received 25th May 2016, Accepted 6th July 2016

DOI: $10.1039 / \mathrm{c} 6 \mathrm{cp} 03600 \mathrm{~g}$

www.rsc.org/pccp

\section{Humidity versus photo-stability of metal halide perovskite films in a polymer matrix $\dagger$}

\author{
Nurul Ain Manshor, ${ }^{a}$ Qamar Wali, ${ }^{a}$ Ka Kan Wong, ${ }^{\mathrm{b}}$ Saifful Kamaluddin Muzakir, ${ }^{a}$ \\ Azhar Fakharuddin, ${ }^{* a b}$ Lukas Schmidt-Mende ${ }^{b}$ and Rajan Jose ${ }^{* a}$
}

\begin{abstract}
Despite the high efficiency of over $21 \%$ reported for emerging thin film perovskite solar cells, one of the key issues prior to their commercial deployment is to attain their long term stability under ambient and outdoor conditions. The instability in perovskite is widely conceived to be humidity induced due to the water solubility of its initial precursors, which leads to decomposition of the perovskite crystal structure; however, we note that humidity alone is not the major degradation factor and it is rather the photon dose in combination with humidity exposure that triggers the instability. In our experiment, which is designed to decouple the effect of humidity and light on perovskite degradation, we investigate the shelf-lifetime of $\mathrm{CH}_{3} \mathrm{NH}_{3} \mathrm{Pbl}_{3}$ films in the dark and under illumination under high humidity conditions (Rel. $\mathrm{H} .>70 \%$ ). We note minor degradation in perovskite films stored in a humid dark environment whereas upon exposure to light, the films undergo drastic degradation, primarily owing to the reactive $\mathrm{TiO}_{2} /$ perovskite interface and also the surface defects of $\mathrm{TiO}_{2}$. To enhance its air-stability, we incorporate $\mathrm{CH}_{3} \mathrm{NH}_{3} \mathrm{Pbl}_{3}$ perovskite in a polymer (poly-vinylpyrrolidone, PVP) matrix which retained its optical and structural characteristics in the dark for $\sim 2000 \mathrm{~h}$ and $\sim 800 \mathrm{~h}$ in room light soaking, significantly higher than a pristine perovskite film, which degraded completely in $600 \mathrm{~h}$ in the dark and in less than $100 \mathrm{~h}$ when exposed to light. We attribute the superior stability of PVP incorporated perovskite films to the improved structural stability of $\mathrm{CH}_{3} \mathrm{NH}_{3} \mathrm{Pbl}_{3}$ and also to the improved $\mathrm{TiO}_{2}$ /perovskite interface upon incorporating a polymer matrix. Charge injection from the polymer embedded perovskite films has also been confirmed by fabricating solar cells using them, thereby providing a promising future research pathway for stable and efficient perovskite solar cells.
\end{abstract}

\section{Introduction}

The remarkable improvement in the photoconversion efficiency (PCE) of organometallic halide perovskite solar cells (PSCs) from an initial $3.8 \%$ in $2009^{1}$ to $>21 \%$ in $2016^{2}$ has taken the research community by surprise. The increase in the PCE is due to optimization of typically employed perovskite $\left(\mathrm{CH}_{3} \mathrm{NH}_{3} \mathrm{PbX}_{3}\right.$, where $\mathrm{X}=\mathrm{I}$, $\mathrm{Cl}, \mathrm{Br}$ ) by adding formamidinium (FA) and/or cesium (Cs) into a methylammonium cation $(\mathrm{MA})^{2-4}$ and enabling better charge extraction at electron and hole selective contacts. ${ }^{5}$ The global interest in this emerging class of solar cells is due to their high absorption coefficient $\left(1.5 \times 10^{4} \mathrm{~cm}^{-1}\right.$ at $\left.550 \mathrm{~nm}\right){ }^{6}$ ambipolar charge transport, ${ }^{7,8}$ direct band gap $\left(\sim 1.55 \mathrm{eV} \text { for } \mathrm{CH}_{3} \mathrm{NH}_{3} \mathrm{PbI}_{3}\right)^{9}$ and high charge carrier mobility $\left(\sim 66 \mathrm{~cm}^{2} \mathrm{~V}^{-1} \mathrm{~s}^{-1}\right.$ for $\left.\mathrm{CH}_{3} \mathrm{NH}_{3} \mathrm{PbI}_{3}\right)^{10}$ which enables a diffusion length up to $175 \mu \mathrm{m}^{11}$ in single crystals. Despite these excellent properties usually only

\footnotetext{
${ }^{a}$ Nanostructured Renewable Energy Materials Laboratory, Faculty of Industrial Sciences and Technology (FIST), Universiti Malaysia Pahang, 26300 Kuantan, Malaysia.E-mail: azhar.fakhar@yahoo.com, rjose@ump.edu.my

${ }^{b}$ Department of Physics, University of Konstanz, D-78457, Konstanz, Germany

$\dagger$ Electronic supplementary information (ESI) available. See DOI: 10.1039/c6cp03600g
}

found in inorganic semiconductors, high efficiency perovskite films are solution processible under ambient conditions. Although their device design was initially inspired from that of dye-sensitized solar cells, where an absorber layer is anchored to a mesoporous layer of an n-type metal oxide semiconductor such as $\mathrm{TiO}_{2},{ }^{12,13}$ subsequent research on perovskite solar cells (PSCs) demonstrated that the mesoporous layer giving high PCEs of $18-19 \%$ is not needed and scaffold-free (planar) PSCs achieve the same high efficiencies. ${ }^{14,15}$ Similarly, we find reports of high efficiency $(10-13 \%)$ in large area modules, ${ }^{16-19}$ in flexible PSCs $(\sim 15.6 \%),{ }^{20}$ and even the first flexible perovskite solar modules. ${ }^{21}$ PSCs have proven to work in dim-light, ${ }^{22}$ and the possibility of semi-transparency ${ }^{23-25}$ has strengthened their case for a deployable PV technology e.g. for building integration. Despite the remarkable progress shown to improve the PV performance of PSCs, the key challenges prior to their commercial deployment are their toxicity (due to presence of lead) ${ }^{26,27}$ scalability and long-term operational stability. ${ }^{28}$

For a new PV technology to reach the market, it has to offer four key parameters: (i) high efficiency (comparable to thin film and silicon solar cells on the market), (ii) low cost $<\$ 0.05 \mathrm{~kW} \mathrm{~h},{ }^{29}$ to reach grid parity, (iii) long lifetime ( $>20$ years), and (iv) added functionality (flexibility, transparency and aesthetics). ${ }^{30}$ PSCs need 
to be considerably better in at least one of these key parameters and have to match the others to be commercially interesting compared to conventional solar technologies. After the past five years of efficiency driven research on PSCs, the focus now is shifting to understanding the underlying processes governing the high efficiency and also to obtaining long-term stable devices. PSCs are known to degrade under outdoor conditions such as humidity, oxygen, temperature, UV light, intense light irradiation and also when they are under the effect of an electric field. ${ }^{31-33}$ Whereas humidity induced instability in these devices arises from the fact that the initial precursors employed to synthesize perovskites, i.e., $\mathrm{CH}_{3} \mathrm{NH}_{3} \mathrm{PbI}_{3}$, are water soluble, the reasons for photodegradation, particularly at low light, are not yet clear despite the initial reports. ${ }^{34,35}$ Due to the humidity sensitive nature of these perovskites, their thin films are often prepared in situ which may hinder their mass production. However, when exposed to outdoor conditions, perovskite films undergo structural and morphological changes which affect their optical properties and consequently results in the decrease of their PV performance over time. For example, a significant decrease in device performance is reported in the presence of moisture when a $\mathrm{CH}_{3} \mathrm{NH}_{3} \mathrm{PbI}_{3}$ perovskite film undergoes rapid decomposition to $\mathrm{PbI}_{2}$ (as evident from the change of color from dark brown to yellow). ${ }^{36,37}$ Yang et al. observed that, besides humidity, molecular oxygen and light can also lead to decomposition of $\mathrm{CH}_{3} \mathrm{NH}_{3} \mathrm{PbI}_{3}{ }^{38} \mathrm{~A}$ report from Aristidou et al. also affirmed decomposition of $\mathrm{CH}_{3} \mathrm{NH}_{3} \mathrm{PbI}_{3}$ to $\mathrm{PbI}_{2}$ and $\mathrm{I}_{2}$, and methylamine under ambient conditions. ${ }^{39}$

It is important to note that although humidity is reported to affect the long-term stability of PSCs, controlled moisture is one of the prerequisites to obtain high photoluminescence and thereby a high PCE in perovskite films. ${ }^{40}$ Controlled moisture reduces trap states due to the partial solvation of the MA ion and allow "self-healing" of the perovskite crystal. ${ }^{41}$ However, excess humidity is shown to decompose perovskite crystals due to their water solubility. ${ }^{42,43}$ Various strategies such as device encapsulation to avoid moisture ingress, incorporation of UV-filters to avoid UV-induced instability or device fabrication and packaging under inert conditions prior to their exposure to ambient conditions are proposed to overcome humidity instability. ${ }^{44,45}$ However, such strategies lead to the increase of device fabrication cost and also add difficulties in device fabrication. In order to fully obtain the key features of easy processability and roll-to-roll compatible mass production, not only do perovskite thin films need to be synthesized under ambient conditions but also, more importantly, their structural, optical and morphological characteristics need to be maintained during their long-term operation under outdoor conditions.

Besides external factors such as humidity, oxygen, temperature and light (including UV) irradiation, the perovskite layer is also known to degrade internally by reacting with the $\mathrm{TiO}_{2}$ nanoparticle (NP) layer underneath, as also suggested in our previous reports. ${ }^{18,46}$ Such a reactive interface might lead to ion migration across the interface. The surface defects on $\mathrm{TiO}_{2}$ nanocrystals have also been shown to act as a humidity trap leading to decomposition of perovskite crystals which is overcome by post treatment of $\mathrm{TiO}_{2}$ layers with $\mathrm{CdS},{ }^{47}$ and $\mathrm{Sb}_{2} \mathrm{~S}_{3}{ }^{48}$ to avoid surface degradation. In a similar study, Li et $a .^{49}$ used caesium bromide $(\mathrm{CsBr})$ to modify the $\mathrm{TiO}_{2}$ interface to improve the photocatalytic activity of the device and also reduced interfacial defect sites. It is thereby evident that optimization of the $\mathrm{TiO}_{2} /$ $\mathrm{CH}_{3} \mathrm{NH}_{3} \mathrm{PbI}_{3}$ interface is crucial to improve the photocatalytic properties of the device, not only to protect it from external stress factors but also to avoid a possible reaction of perovskite with the selective contact underneath. The research on exploring the role of interfacial degradation becomes more intriguing after the report that perovskite films, by themselves, can withstand humidity and it is rather the photon dose that leads to device degradation. ${ }^{50}$ A systematic experiment to decouple the humidity and light stability of perovskite films is therefore crucial in order to understand the origin of such a degradation.

Herein, we report a systematic experiment to investigate the stability of a $\mathrm{CH}_{3} \mathrm{NH}_{3} \mathrm{PbI}_{3}$ thin film in light as well as in the dark under high humidity conditions (Rel. H. 70-80\%) to investigate the origin of instability. We then synthesize a $\mathrm{CH}_{3} \mathrm{NH}_{3} \mathrm{PbI}_{3}$-poly-(vinylpyrrolidone) (PVP) matrix to protect it from humidity, oxygen and light and to further investigate the role of interfacial degradation. A systematic investigation of polymer embedded perovskite (PeP) films at different concentrations ( $0 \mathrm{wt} \%, 5 \mathrm{wt} \%, 10 \mathrm{wt} \%$ \& $20 \mathrm{wt} \%$ ) demonstrated many fold enhanced air stability of $\mathrm{CH}_{3} \mathrm{NH}_{3} \mathrm{PbI}_{3}$ films. The morphological, structural and optical investigation of PeP thin films under such high humidity conditions showed that they were stable even after $2000 \mathrm{~h}$ of shelf-life testing in the dark and $\sim 800 \mathrm{~h}$ in room light soaking, significantly higher than a pristine perovskite film (stable for $<600 \mathrm{~h}$ in the dark and in $<100 \mathrm{~h}$ in light). It is noteworthy that the first demonstration of perovskite films in a polymer (PEG) was recently reported with a PCE of $\sim 16 \%$; however the focus of the study was towards humidity stability only. ${ }^{51}$ We report a detailed analysis of perovskite films in order to understand the reasons for the stable performance of PeP films and the different degradation mechanisms in humidity only and 'humidity coupled with light'.

\section{Experimental}

\subsection{Materials}

Titanium dioxide paste (Ti-Nanoxide, T/SP, Solaronix), methylammonium $\left(\mathrm{CH}_{3} \mathrm{NH}_{2}\right.$, R\&M Chemical, $40 \mathrm{wt} \%$ in aqueous solution), hydroiodic acid (HI, Sigma Aldrich, $57 \mathrm{wt} \%$ in water), $N, N$ dimethylformamide (DMF, Merck), lead iodide $\left(\mathrm{PbI}_{2}\right.$, Sigma Aldrich, 98\%), and polyvinylpyrrolidone (PVP, R\&M Company, $160000 \mathrm{~g} \mathrm{~mol}^{-1}$ ) were used to form material active layers.

\subsection{Processing of perovskite films at high humidity}

Glass plates that are used as a substrate to deposit perovskite films were sequentially cleaned with detergent, acetone and ethanol under sonication for $15 \mathrm{~min}$ each. Mesoporous $\mathrm{TiO}_{2}$ $\left(\mathrm{mp}-\mathrm{TiO}_{2}\right)$ paste was diluted in absolute ethanol at a volumetric ratio $(1: 2)$ and was spin coated onto the cleaned glass slides at 
$2000 \mathrm{rpm}$ for $40 \mathrm{~s}$ to form a mesoporous scaffold layer. The films were dried on a hotplate at $100{ }^{\circ} \mathrm{C}$ for $15 \mathrm{~min}$ prior to annealing at $450{ }^{\circ} \mathrm{C}$ for $30 \mathrm{~min}$ in air to evaporate the organic binder in the $\mathrm{TiO}_{2}$ paste. The $\mathrm{CH}_{3} \mathrm{NH}_{3} \mathrm{PbI}_{3}$ precursor solution was synthesized by dissolving $\mathrm{CH}_{3} \mathrm{NH}_{3} \mathrm{I}$ and $\mathrm{PbI}_{2}$ (1:1 molar ratio) in $40 \mathrm{wt} \%$ solution of anhydrous DMF and stirring at $80{ }^{\circ} \mathrm{C}$ for $3 \mathrm{~h}$. This solution was spin casted onto $\mathrm{mp}-\mathrm{TiO}_{2} /$ glass films at $2000 \mathrm{rpm}$ for $40 \mathrm{~s}$ and sintered $\left(100{ }^{\circ} \mathrm{C}\right.$ for $1 \mathrm{~h}$ and $125{ }^{\circ} \mathrm{C}$ for $15 \mathrm{~min}$ ) to form $\mathrm{CH}_{3} \mathrm{NH}_{3} \mathrm{PbI}_{3}$ crystals. To improve the surface coverage of perovskite, the $\mathrm{TiO}_{2}$ coated glass substrates were preheated at $100{ }^{\circ} \mathrm{C}$. The deposition was carried out at room temperature $\left(25-30{ }^{\circ} \mathrm{C}\right)$ and high humidity (70-80\%).

\subsection{Polymer-perovskite matrix for air stable films}

In order to improve the air-stability of perovskite films, $\mathrm{CH}_{3} \mathrm{NH}_{3} \mathrm{PbI}_{3}$ was embedded in a PVP matrix (PPM). A given amount of PVP powder was added to perovskite precursors during solution synthesis to form PPM in the following weight ratio of perovskite: PVP: (i) $100: 0$, (ii) $95: 5$, (iii) $90: 10$, and (iv) $80: 20$. The samples will be denoted as $0 \%, 5 \%, 10 \%$ and $20 \%$ throughout the article and the label assigned corresponds to the ratio of PVP to perovskite in a particular PeP film. To synthesize $\mathrm{CH}_{3} \mathrm{NH}_{3} \mathrm{PbI}_{3}-\mathrm{PVP}$ matrix solution and to deposit it on the $\mathrm{mp}-\mathrm{TiO}_{2}$ coated glass substrate, the procedure as described before has been repeated.

\subsection{Shelf-life testing to investigate air stability of perovskite films}

To investigate thin film stability, we adopted the 'ISOS-D-1 Shelf' protocol as reported in the literature..$^{52-54}$ The pure and polymer coated perovskite films were stored in (i) dark (in a desiccator $\sim 25-30{ }^{\circ} \mathrm{C}, 55-70 \%$ Rel. H.) and in room light (light intensity $\sim 5 \mathrm{~mW} \mathrm{~cm}{ }^{-2}, 25-30{ }^{\circ} \mathrm{C}, 70-80 \%$ Rel. H.). The shelf life is monitored until degradation is tracked in each sample which is confirmed from their (i) change in color, (ii) relative changes in the absorbance and photoluminescence, and (iii) XRD spectra. The lifetime of each sample with different polymer concentrations kept in light or in the dark was noted in order to measure the lifetime of each film. In order to probe the degradation of the films and the failure mechanism, we carried out their surface characterization using field emission scanning electron microscopy (FESEM, JEOL), optical characterization techniques such as UV-visible absorption (UV-2600, Shimadzu) and photoluminescence (PL, NIR 300/2 Edinburgh), and chemical and structural characterization using X-ray diffraction (XRD) and Fourier transform infrared spectroscopy (FTIR).

\subsection{Fabrication of perovskite solar cells and characterization}

PSCs employing pure perovskite and their polymer incorporating counterparts were fabricated in an inert atmosphere. The details of fabrication are given in the ESI. $\dagger$ The photovoltaic performance of the PSCs is measured using an AM 1.5G solar simulator in an inert atmosphere at a light intensity of $\sim 85 \mathrm{~mW} \mathrm{~cm}^{-2}$ and using a Fraunhofer ISE certified Si reference diode with an attached KG5 filter. A shadow mask defined the active area of $\sim 0.125 \mathrm{~cm}^{2}$ for the PSCs.

\section{Results and discussion}

3.1 Synthesis and shelf-life analysis of perovskite films under high humidity conditions

Fig. 1a shows a cross sectional view of the $\mathrm{CH}_{3} \mathrm{NH}_{3} \mathrm{PbI}_{3}$ thin film (500-600 nm) coated over a mesoporous $\mathrm{TiO}_{2}$ layer $(\sim 500 \mathrm{~nm})$. Clearly, the high humidity (70-80\%) favoured growth of a dense film with large $\mathrm{CH}_{3} \mathrm{NH}_{3} \mathrm{PbI}_{3}$ crystals (size up to 200-250 nm), contrary to the perovskite films synthesized in an inert atmosphere in our previous reports (Fig. SI-1, ESI $\dagger$ ) with a smaller crystal size and large grain boundary density. This is due to the fact that humidity may induce grain creeps resulting in merging of neighbouring perovskite grains. ${ }^{55}$ The larger $\mathrm{CH}_{3} \mathrm{NH}_{3} \mathrm{PbI}_{3}$ crystals obtained in the present work with less grain boundaries may result in efficient charge transport across the perovskite film. The bandgap of perovskite films calculated using the Tauc plot is $\sim 1.55 \mathrm{eV}$ and the emission peak is at $778 \mathrm{~nm}$ which matches with the values reported in the literature. ${ }^{56-58}$ The perovskite films absorb most of the visible light $<600 \mathrm{~nm}$ which gradually decreases in the 600-780 nm range (Fig. 2c).
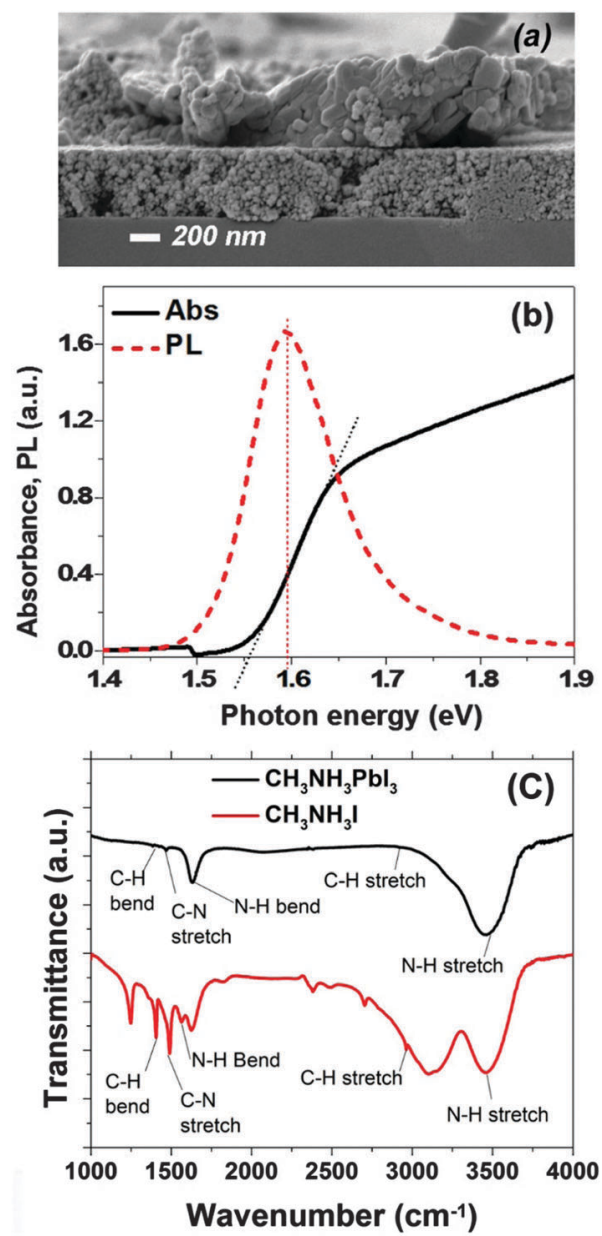

Fig. 1 Cross-sectional FESEM image of a fresh perovskite film (glass $/ \mathrm{TiO}_{2} /$ $\mathrm{CH}_{3} \mathrm{NH}_{3} \mathrm{Pbl}_{3}$ ) showing perovskite crystals of $200-300 \mathrm{~nm}$ size, (b) absorbance and emission intensity of the same as a function of photon energy used to calculate the bandgap of $\mathrm{CH}_{3} \mathrm{NH}_{3} \mathrm{Pbl}_{3}$ (1.55 eV), and (c) FTIR spectra of $\mathrm{CH}_{3} \mathrm{NH}_{3} \mathrm{I}$ and $\mathrm{CH}_{3} \mathrm{NH}_{3} \mathrm{Pbl}_{3}$. 

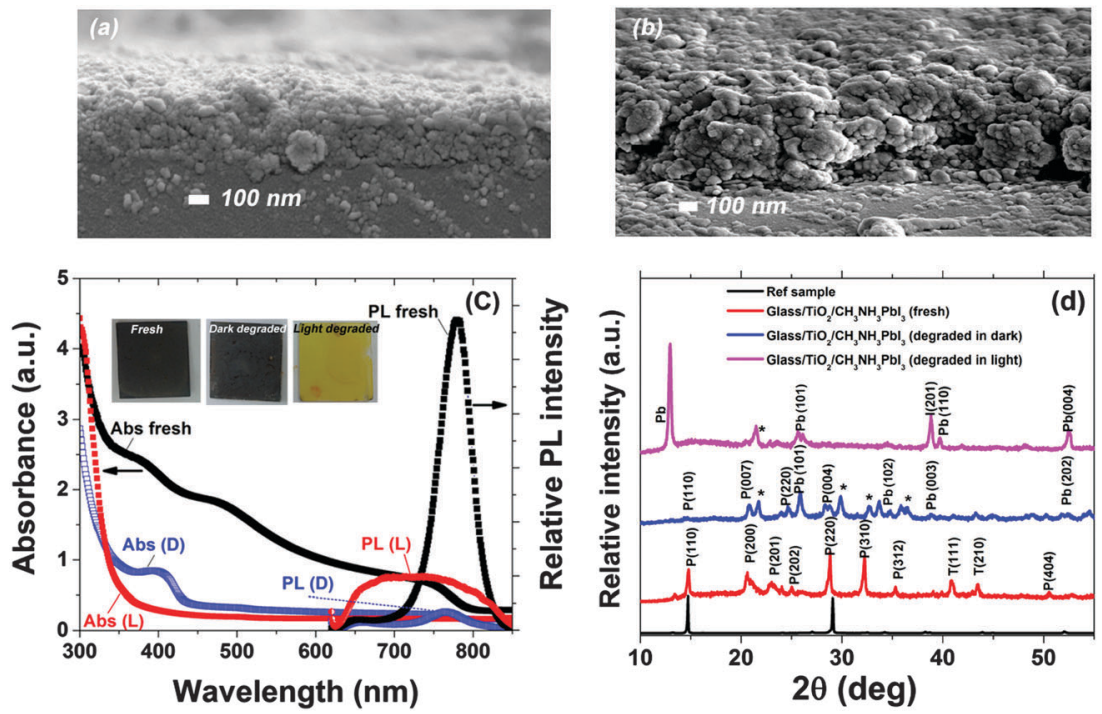

Fig. 2 FESEM images of the $\mathrm{CH}_{3} \mathrm{NH}_{3} \mathrm{Pbl}_{3}$ film stored under high humidity conditions (Rel. H. 70-80\%) and exposed to (a) the dark for $600 \mathrm{~h}$, and (b) light for merely $\sim 100 \mathrm{~h}$ showing the degree of decomposition of the perovskite crystal structure. Figure (c) compares absorbance (left) and PL (on right) of the three films (fresh, in the dark and in light at high humidity). The inset shows a photograph of the same, and (d) compares the XRD spectra of the three with a reference perovskite film prepared in a glove box. The reference XRD is taken from our previous report. ${ }^{18}$

In order to validate the presence of methyl amine (MAI) in $\mathrm{PbI}_{2}$, i.e., formation of $\mathrm{CH}_{3} \mathrm{NH}_{3} \mathrm{PbI}_{3}$, we carried out FTIR measurements. The FTIR transmittance spectrum is recorded in the range 500$4000 \mathrm{~cm}^{-1}$ (data from 1000-4000 $\mathrm{cm}^{-1}$ are only shown in Fig. 1c). The peaks recorded for symmetrical and asymmetrical vibrations in MAI are at 3459, 2959, 1560, 1489, and $1404 \mathrm{~cm}^{-1}$ which correspond to $\mathrm{N}-\mathrm{H}$ stretching, $\mathrm{C}-\mathrm{H}$ stretching, $\mathrm{N}-\mathrm{H}$ bending, $\mathrm{C}-\mathrm{N}$ stretching and $\mathrm{C}-\mathrm{H}$ bending, respectively whereas in the case of $\mathrm{CH}_{3} \mathrm{NH}_{3} \mathrm{PbI}_{3}$, the corresponding peaks are at 3452, 2925, $1627,1460,1382 \mathrm{~cm}^{-1}$. The shift and peak broadening observed in the case of perovskite is due to the interaction of MAI with $\mathrm{PbI}_{2}$ that results in a shift in the corresponding symmetrical and asymmetrical vibrations.

As the prime focus of this article is to investigate air stability of perovskite thin films, we carried out shelf-life testing of our samples kept in (i) the dark and (ii) room light in order to understand the effect of humidity, oxygen and also light exposure. The room temperature was $25-30{ }^{\circ} \mathrm{C}$ and the humidity varied between 70 and $80 \%$. The samples were tested unless a complete decay in their optical properties (absorbance and PL) and also decomposition of perovskite crystals is confirmed via XRD. Fig. $2 \mathrm{a}$ and $\mathrm{b}$ shows FESEM micrographs of the degraded samples after $600 \mathrm{~h}$ and $100 \mathrm{~h}$ in the dark and room light, respectively. Although the total film thickness $\left(\mathrm{TiO}_{2}+\mathrm{CH}_{3} \mathrm{NH}_{3} \mathrm{PbI}_{3}\right)$ remained almost the same (900-1000 nm), a distinction between $\mathrm{TiO}_{2}$ and perovskite layers is not possible anymore and the perovskite crystals seem to be decomposed and diffused into the mesoporous $\mathrm{TiO}_{2}$. Surprisingly the degradation pattern of the two samples (dark and light) is notably different. The films kept in the dark, upon degradation, did not show any presence of $\mathrm{PbI}_{2}$, which is contrary to the common understanding that $\mathrm{CH}_{3} \mathrm{NH}_{3} \mathrm{PbI}_{3}$ decomposes to $\mathrm{PbI}_{2}$ in the presence of humidity. This could be verified from the photographs of the aged samples (Fig. 2c, inset, labelled as dark degraded) which still shows a dark brown color associated with perovskite crystals. Although the UV-spectrum of these films showed a considerable drop in relative absorbance, the absorbance spectrum still shows characteristics of perovskite. The presence of perovskite is also confirmed from the emission peak related to perovskite at $\sim 770 \mathrm{~nm}$ although PL spectra showed $\sim 20$ times reduction in the relative intensity. On the other hand, the samples kept in room light showed the presence of $\mathrm{PbI}_{2}$ as a color change is observed from dark brown to yellow (Fig. 2c, inset) and also no corresponding perovskite absorbance or PL peaks are visible. The absorbance features of these films correspond to $\mathrm{PbI}_{2}$ which also matches with its absorbance characteristics reported in the literature $(<350 \mathrm{~nm}) .^{59}$

In order to validate the degradation pattern in these films, we carried out their XRD analysis (Fig. 2d) and compared it with a reference sample prepared in a glove box. ${ }^{18}$ All representative peaks of the fresh film can be indexed to $\mathrm{CH}_{3} \mathrm{NH}_{3} \mathrm{PbI}_{3}$ (labelled as $\mathrm{P}$ ) and $\mathrm{TiO}_{2}$ (labelled as $\mathrm{T}$ ). It is important to note that the XRD spectra of the perovskite films prepared under high humidity conditions show broadened peaks related to a much larger size of perovskite crystal compared to those prepared under inert conditions as in our previous report where a small perovskite crystal size showed sharp intensity peaks. ${ }^{18}$ Interestingly, even after $>600 \mathrm{~h}$ of shelf-life testing, the perovskite films kept in the dark did not show contents of $\mathrm{PbI}_{2}$ or $\mathrm{I}_{2}$ (major peaks at $2 \theta \sim 12.8^{\circ}$ and $\sim 38.8^{\circ}$, respectively) which are widely believed to be present in decomposed films. Although the major peak of perovskite at $2 \theta \sim 14.8^{\circ}$ nearly vanishes, the XRD spectrum of the aged perovskite film in the dark (blue line) can still be indexed to various perovskite phases at $2 \theta \sim 20.8^{\circ}$, $24.6^{\circ}, 28.2^{\circ}, 28.76^{\circ}$, and $35.86^{\circ}$. On the other hand, the samples exposed to light showed a notable presence of $\mathrm{PbI}_{2}\left(2 \theta \sim 12.8^{\circ}\right)$ and $\mathrm{I}_{2}\left(2 \theta \sim 38.8^{\circ}\right)$ even $\sim 50-100 \mathrm{~h}$ of room light exposure 
which affirms the presence of $\mathrm{PbI}_{2}$ as from their change in color (Fig. 2c, inset). Surprisingly, no peaks for perovskite can be found in the XRD spectrum of the degraded sample (Fig. 2d, pink line) which explains why emission and absorbance features of perovskite are not present in its respective spectrum.

Contrary to the widely established understanding that perovskite films are extremely sensitive to humidity, our results suggest that this is not the case. The $\mathrm{CH}_{3} \mathrm{NH}_{3} \mathrm{PbI}_{3}$ films showed little dependence on humidity and major degradation only occurs when the samples are exposed to photon dose. In fact a similar observation was also made by Matsumoto et al. ${ }^{50}$ that a perovskite layer itself is stable when exposed to humidity; however, the authors noted that the nature of the $\mathrm{TiO}_{2} /$ perovskite interface plays a dominant role in degradation, as also observed previously. ${ }^{60,61}$ The small degradation of our samples in the dark (even after $600 \mathrm{~h}$ ) and rapid degradation in merely $\sim 100 \mathrm{~h}$ in light suggests that the nature of the $\mathrm{TiO}_{2} /$ perovskite interface is highly sensitive to light. Perhaps, upon exposure to light, the $\mathrm{TiO}_{2}$ thin layer, which is known to be reactive with $\mathrm{CH}_{3} \mathrm{NH}_{3} \mathrm{PbI}_{3},{ }^{18,48,49}$ tends to react much rapidly leading to a surface degradation of perovskite. This could also explain the presence of a few unknown peaks in the XRD spectrum (marked by $\mathrm{a}^{*}$ ), which may be related to intermediate phases formed by $\mathrm{TiO}_{2} /$ perovskite. Nonetheless, it is noteworthy that the degradation of $\mathrm{CH}_{3} \mathrm{NH}_{3} \mathrm{PbI}_{3}$ films in light took place $\sim 12$ times faster compared to the samples placed in the dark suggesting that the $\mathrm{TiO}_{2}$ surface defects - which are known as a humidity site - are triggered upon exposure to light leading to a drastic decomposition of perovskite films.

\subsection{Polymer incorporating perovskite films and enhanced air stability}

Our results suggest that it is rather the photon dose coupled to humidity that induces instability in perovskite films instead of humidity alone. Towards this, the $\mathrm{TiO}_{2} / \mathrm{CH}_{3} \mathrm{NH}_{3} \mathrm{PbI}_{3}$ interface, which is known to react with perovskite owing to the surface defects in $\mathrm{TiO}_{2}{ }^{18,48}$ plays a major role. To overcome this, we synthesised the $\mathrm{CH}_{3} \mathrm{NH}_{3} \mathrm{PbI}_{3}-\mathrm{PVP}$ matrix at different concentrations of PVP (5 wt $\%, 10 \mathrm{wt} \%$ \& $20 \mathrm{wt} \%$ ) and investigated variations in their surface properties as a function of time. It is important to note that for each type of device tested in the dark and in light, the aging time varies. This is because the devices were tested until a notable degradation is observed in order to track their air stability. Fig. 3a-l shows three types of surface images of each device $(0,5,10$, and $20 \mathrm{wt} \% \mathrm{PVP})$. Each wt $\%$ represents the concentration of $\mathrm{PVP}$ which is added to the perovskite solution. The pristine $\mathrm{CH}_{3} \mathrm{NH}_{3} \mathrm{PbI}_{3}$ films with $0 \mathrm{wt} \%$ (Fig. 3a-c) degraded within $\sim 600 \mathrm{~h}$ in the dark and $<100 \mathrm{~h}$ when exposed to light showing decomposition in perovskite crystals. Whereas the fresh $\mathrm{CH}_{3} \mathrm{NH}_{3} \mathrm{PbI}_{3}$ films show crystals with a size of $\sim 100-250 \mathrm{~nm}$ and perovskite and $\mathrm{TiO}_{2}$ layers are distinguishable, the sample after shelf-life testing in light and in the dark shows that the perovskite film is diffused in mesoporous $\mathrm{TiO}_{2}$. Not only are the two layers not distinguishable anymore after
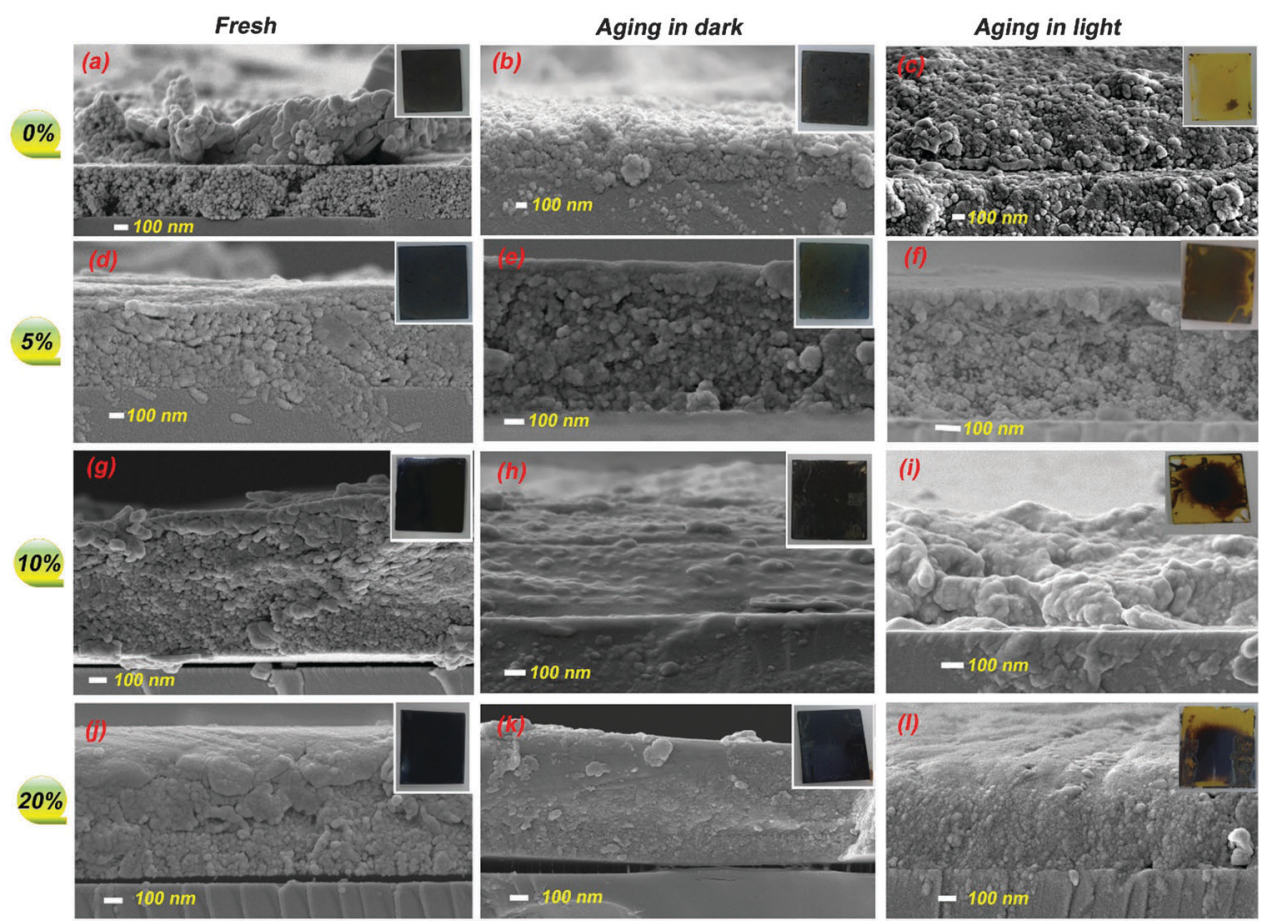

Fig. 3 Representative cross sectional FESEM images of all the pure and PVP-incorporated perovskite films (fresh, in the dark and light stored at high humidity) and recorded after a notable degradation is tracked in each film; i.e., (a-c) 0 wt\% PVP (600 h in the dark, 100 in light), (d-f) $5 \mathrm{wt} \%$ PVP (800 h in the dark, 300 in light), (g-i) $10 \mathrm{wt} \%$ PVP (1800 $\mathrm{h}$ in the dark, $600 \mathrm{in} \mathrm{light),} \mathrm{and} \mathrm{(j-l)} 20 \mathrm{wt} \%$ PVP (2000 $\mathrm{h}$ in the dark, 800 in light). The inset of each figure shows a photograph of the same thin film. 
degradation, but a reduction of $\sim 150-250 \mathrm{~nm}$ is also observed in the total film thickness (employing $\mathrm{CH}_{3} \mathrm{NH}_{3} \mathrm{PbI}_{3}$ and $\mathrm{TiO}_{2}$ ) which changed from $\sim 900-1100 \mathrm{~nm}$ to $\sim 750-950 \mathrm{~nm}$. Interestingly, no color change is observed for the $\mathrm{CH}_{3} \mathrm{NH}_{3} \mathrm{PbI}_{3}$ films kept in the dark suggesting (inset Fig. 3b) no decomposition to $\mathrm{PbI}_{2}$, whereas when exposed to light the presence of $\mathrm{PbI}_{2}$ is evidenced from a change in the color of the perovskite film from dark brown to yellow (inset Fig. 3c). Furthermore, the films exposed to light seem to suffer from more intense degradation despite their $\sim 7$ times shorter shelf-life $(\sim 100 \mathrm{~h})$ compared to the film in the dark $(\sim 600 \mathrm{~h})$ suggesting photon-induced degradation to be more dominant than that by humidity.

Upon incorporation of perovskite into PVP, a two-fold change is noticed in the resultant PeP films: not only had the crystallite size reduced significantly from $\sim 200-250 \mathrm{~nm}$ to $<100 \mathrm{~nm}$ but also, a clear distinction between $\mathrm{CH}_{3} \mathrm{NH}_{3} \mathrm{PbI}_{3}$ and $\mathrm{TiO}_{2}$ is hard to be made. The thickness of the perovskite layer systematically increased from $\sim 500-600 \mathrm{~nm}$ to up to $>1 \mu \mathrm{m}$ in $20 \mathrm{wt} \%$ PVP concentration, which is attributed to the higher solution viscosity of the final polymer-perovskite solution. It is interesting to note that, at higher PVP concentrations (10 wt $\%$ and $20 \mathrm{wt} \%$ ), the perovskite crystals started to agglomerate and the films are very densely packed with a pinhole free texture. Towards their shelf-life testing, the PeP film survived surface degradation even when exposed to dual stress factors; i.e., humidity and light (Fig. 3e, f, h, i, k and l). While the polymer layer seems to retard the humidityinduced instability, it also avoided interfacial degradation of $\mathrm{CH}_{3} \mathrm{NH}_{3} \mathrm{PbI}_{3}$ by making the perovskite/TiO $\mathrm{Tin}_{2}$ interface less reactive. Also, unlike the pristine $\mathrm{CH}_{3} \mathrm{NH}_{3} \mathrm{PbI}_{3}$ film, there is no notable variation in the surface properties of the perovskite film and their thickness is observed in the dark as well as when exposed to light. For the PeP films exposed to humidity and kept in the dark, the presence of $\mathrm{PbI}_{2}$ is not observed (a color change to yellow) although the slight color change from dark to light brown is observed (inset of Fig. 3e, h and k) suggesting structural variations in $\mathrm{CH}_{3} \mathrm{NH}_{3} \mathrm{PbI}_{3}$. However, when exposed to light, the 5, 10 and $20 \mathrm{wt} \% \mathrm{PeP}$ films showed resistance to degradation, especially in the region where perovskite is coated over the $\mathrm{TiO}_{2}$ Electron transport layer (ETL) (inset of Fig. 3f, i and l), unlike the pristine $\mathrm{CH}_{3} \mathrm{NH}_{3} \mathrm{PbI}_{3}$ film which is completely converted to $\mathrm{PbI}_{2}$, as evidenced from their color change (Fig. 3c).

In order to understand the optical properties of PeP films, we carried out absorbance and photoluminescence (PL) measurements (Fig. 4a and b). The PeP films showed a systematic increase in absorbance throughout the visible spectrum and a steeper absorption onset is observed in PeP films (10 and $20 \mathrm{wt} \%$ ). We attribute such an extended absorption onset to the light scattering phenomena in the PeP films owing to the formation of polymer-perovskite or perovskite agglomerates. The increase in the absorption coefficient throughout the visible spectrum range can be attributed to the higher film thickness of the PeP films, which increases systematically from a pure $\mathrm{CH}_{3} \mathrm{NH}_{3} \mathrm{PbI}_{3}$ film with increasing PVP concentration. The PL spectra (Fig. 4b) showed a systematic blue shift in the emission peak upon increasing the PVP concentration; the
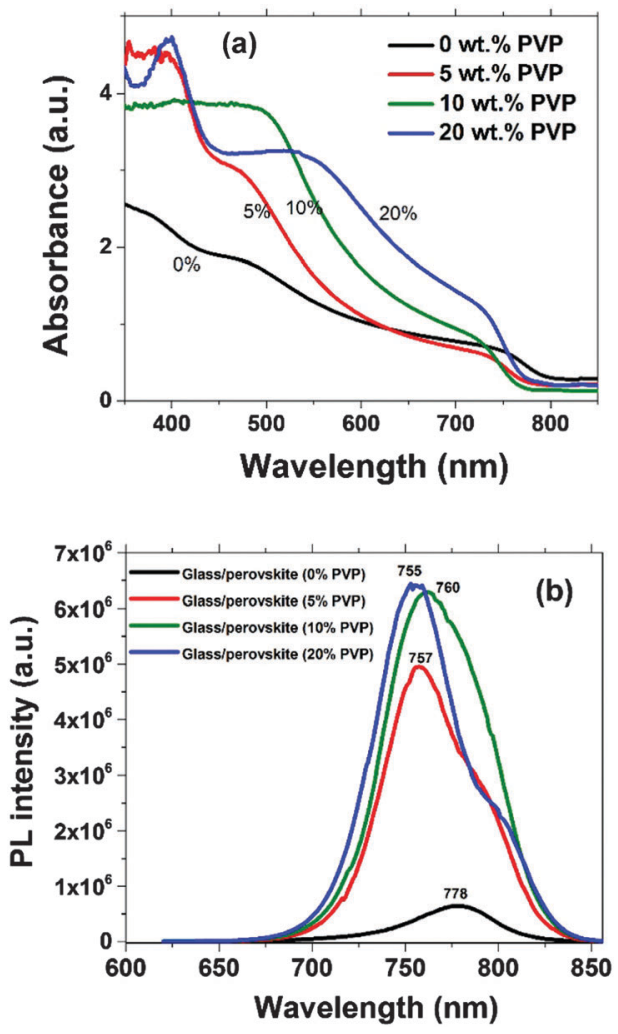

Fig. 4 (a) Absorbance and (b) PL spectra of the pure and PVPincorporated perovskite films on a glass substrate (fresh).

emission peaks observed for pure $\mathrm{CH}_{3} \mathrm{NH}_{3} \mathrm{PbI}_{3}$ (0 wt\%), 5, 10, and $20 \mathrm{wt} \%$ samples were at 77, 757, 760 and $755 \mathrm{~nm}$. The blue shift observed in the PeP films is because the $\mathrm{CH}_{3} \mathrm{NH}_{3} \mathrm{PbI}_{3}$ is grown in a PVP matrix with physical constraints to the growth of perovskite crystals, which is known to induce a blue shift in the PL emission peak. ${ }^{62}$ The PeP films show many orders of magnitude higher PL intensity despite nearly the same absorbance indicating the removal of surface traps due to polymer passivation leading to improved emission properties. This is due to the fact that the PL intensity is in fact a measure of the photogenerated charges in semiconductors which depends on the electron/hole pairs generated by incident light. ${ }^{63,64}$ Furthermore, the higher PL intensity in the PeP films can also be attributed to relaxation of perovskite crystals upon incorporation of the polymer.

The recombination properties of light excited electrons and holes in semiconductors can be explored using PL spectra. Fig. SI-2 (ESI $\dagger$ ) showed the PL spectra of perovskite films interfaced with $\mathrm{TiO}_{2}$ to quantify their charge transfer characteristics. Whereas the PL intensity of glass $/ \mathrm{TiO}_{2} / \mathrm{CH}_{3} \mathrm{NH}_{3} \mathrm{PbI}_{3} / 0 \mathrm{wt} \%$ PVP is quenched to $\sim 80 \%$ of its original value showing effective charge transfer properties, the increasing PVP concentration showed a systematic reduction in PL quenching such that the PL intensity of glass $/ 20$ wt $\%$ PeP $<$ glass $/ 10$ wt $\%$ PeP $<$ glass $/ 5 \mathrm{wt} \% \mathrm{PeP}<$ glass $/ 0 \mathrm{wt} \%$. The reduced charge transfer across the $\mathrm{TiO}_{2} / \mathrm{CH}_{3} \mathrm{NH}_{3} \mathrm{PbI}_{3}$ interface in PeP films could be related to the inferior electronic transport of the polymer 
incorporating film as the conductivity of PVP is several orders of magnitude lower than that of perovskite. No notable peak shift is observed in PeP upon interfacing with $\mathrm{TiO}_{2}$; however, the $20 \mathrm{wt} \%$ PeP film showed two emission peaks (732 and $785 \mathrm{~nm}$ ), the origin of which is not clear at the moment.

We carried out absorbance and PL measurements of the pure and PVP incorporated perovskite films as a function of time stored in the dark and also in room light to investigate their air-stability (ESI, $\dagger$ Fig. SI-3-6). For the samples kept in the dark, the absorbance of pure $\mathrm{CH}_{3} \mathrm{NH}_{3} \mathrm{PbI}_{3}$ and $5 \mathrm{wt} \% \mathrm{PVP}-$ $\mathrm{CH}_{3} \mathrm{NH}_{3} \mathrm{PbI}_{3}$ films showed a notable drop while maintaining the absorbance features of perovskite (Fig. SI-3a-d, ESI $\dagger$ ). This suggests that although a reduction in relative absorbance is noted, the films have not decomposed to their initial precursors (MAI and $\mathrm{PbI}_{2}$ ), at least notably. The significant drop in absorbance could be attributed to structural decomposition of the perovskite crystal from 3D to 2D. The absorbance in glass/ $\mathrm{TiO}_{2} / \mathrm{CH}_{3} \mathrm{NH}_{3} \mathrm{PbI}_{3}$ films dropped down by one third of its initial value in $\sim 600 \mathrm{~h}$ whereas in glass $/ \mathrm{TiO}_{2} / \mathrm{CH}_{3} \mathrm{NH}_{3} \mathrm{PbI}_{3}-5 \mathrm{wt} \%$-PVP films it dropped to half of its initial value in $\sim 800 \mathrm{~h}$ (Fig. 5a). On the other hand, at higher concentrations of PVP, no notable degradation is observed even after air exposure for $\sim 2000 \mathrm{~h}$. Interestingly, upon exposure to light, drastic degradation is observed even in much shorter shelf-lifetime. Whereas the absorbance in pure glass $/ \mathrm{TiO}_{2} / \mathrm{CH}_{3} \mathrm{NH}_{3} \mathrm{PbI}_{3}$ films dropped nearly completely in merely $100 \mathrm{~h}$ and the resultant UV spectra suggesting complete degradation, a notable reduction in PeP films is noted only after 300,600 , and 800 h only for 5, 10 and 20 wt\% PVP concentrations, respectively (Fig. 5b). It is important to note that the UV spectra of these samples after degradation show the presence of $\mathrm{PbI}_{2}$, the extent of which varies inversely with increasing PVP concentration suggesting that the PeP films resisted decomposition of $\mathrm{CH}_{3} \mathrm{NH}_{3} \mathrm{PbI}_{3}$. This is also visible from the photographs of the devices shown in the insets of Fig. 3a-l.

A similar trend is observed for the emission peaks of the perovskite films in the dark and light (Fig. $5 \mathrm{c}$ and d). Whereas a significant drop in the PL emission intensity is observed after $600 \mathrm{~h}$ in the dark, degradation occurs 6 times faster when exposed to light. The PeP films, on the other hand, showed a relatively stable performance in the dark although a notable reduction in the PL intensity is noticed when exposed to room light. Also importantly, the PL spectra of the corresponding perovskite films kept in the dark retain their characteristics with little variation (5-10) $\mathrm{nm}$ observed in the PL peak intensity; however, the samples exposed to light undergo a drastic variation (Fig. SI-6a-d, ESI $\dagger$ ), the intensity of which is inversely related to PVP concentration. Whereas the pure $\mathrm{CH}_{3} \mathrm{NH}_{3} \mathrm{PbI}_{3}$ films did not show a corresponding PL peak within $\sim 100 \mathrm{~h}$ of light exposure (Fig. SI-6a, ESI $\dagger$ ), the peak disappeared in $5 \mathrm{wt} \%$ PeP films only after $300 \mathrm{~h}$. The 10 and $20 \mathrm{wt} \%$ PeP films still showed a corresponding emission peak evidencing the existence of $\mathrm{CH}_{3} \mathrm{NH}_{3} \mathrm{PbI}_{3}$ (Fig. SI-6b-d, ESI $\dagger$ ). A comparison of the Stokes shifts calculated for the fresh sample $(50,46,32$, and $12 \mathrm{~nm}$ ) and degraded films in the dark (56, 34, 55, and $13 \mathrm{~nm}$ ) shows little variation whereas for the sample exposed to light, the Stokes shift cannot be calculated. This is due to the fact that the absorption onset at $\sim 790 \mathrm{~nm}$ related to perovskite bandedge absorption is not visible anymore and the new onset appears in the range 550-650 $\mathrm{nm}$. The Stokes shift calculated from the new onset for degraded films in light is 3-4 times higher than a corresponding fresh film. Whereas a small Stokes
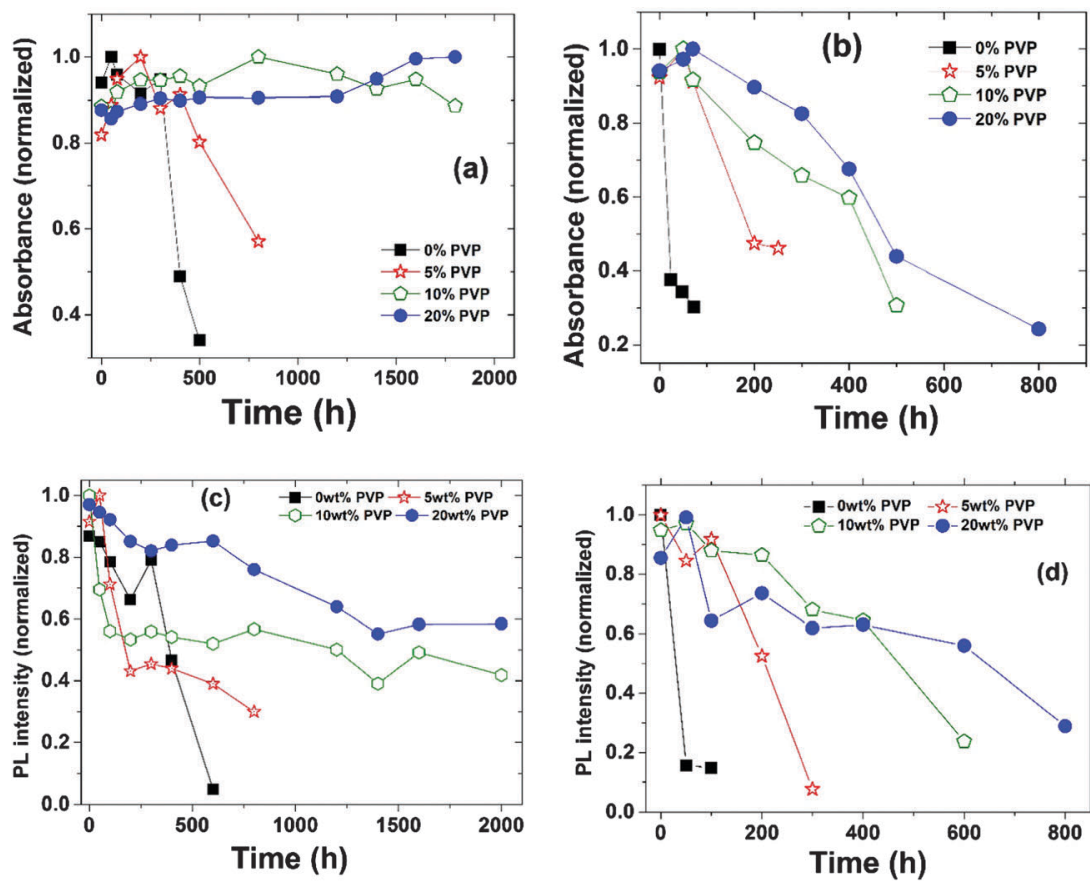

Fig. 5 Absorbance and $\mathrm{PL}$ of $\mathrm{CH}_{3} \mathrm{NH}_{3} \mathrm{Pbl}_{3}$ thin films recorded during shelf-life measurements for representative four types $(0,5,10$, and 20 wt\% PVP) in the dark ( $a$ and $c$ ) and in light ( $b$ and $d$ ) and stored at Rel. $H>70 \%$, respectively. 
shift (samples in dark) is related to band-to-band radiative recombination within $\mathrm{CH}_{3} \mathrm{NH}_{3} \mathrm{PbI}_{3}$, the large Stokes shift (samples in light) can be attributed to surface defects that are created by isolated $\mathrm{PbI}_{2}$ octahedra.l. ${ }^{65}$ Although the optical investigations affirm our initial findings from surface analysis (SEM images) and the change in color of the samples that humidity alone is not the major degradation factor and it is rather the nature of the interface (surface defects of $\mathrm{TiO}_{2}$ ) that is triggered under photon dose, chemical analysis is inevitable to find its origin.

In order to note any variation in the chemical structure we recorded the XRD spectra of the perovksite films kept in the dark and exposed to light (both in high humidity $>70 \%$ ) as a function of time. The corresponding peaks observed in fresh samples can be indexed to $\mathrm{TiO}_{2}$ and $\mathrm{CH}_{3} \mathrm{NH}_{3} \mathrm{PbI}_{3}$ with perovskite major peaks (110), (220), and (330) are visible at $2 \theta \sim 14.8,28.8$ and $43.4^{\circ}$, respectively, suggesting no structural variation upon incorporation of PVP (Fig. 6a). ${ }^{66}$ The presence of amorphous PVP that typically shows corresponding peaks at $2 \theta \sim 22^{\circ}$ is not observed in the PeP films which could be attributed to its low concentration. The XRD spectra of the pure and PVP incorporated $\mathrm{CH}_{3} \mathrm{NH}_{3} \mathrm{PbI}_{3}$ films kept in the dark and exposed to light measured after a notable degradation is tracked via their optical measurements are shown in Fig. 6b and c. Although a structural deformation is observed for the pure $\mathrm{CH}_{3} \mathrm{NH}_{3} \mathrm{PbI}_{3}$ film in the dark after $\sim 600 \mathrm{~h}$ as the peak intensity of $(110)$ at $2 \theta \sim 14.8^{\circ}$ is significantly dropped, no corresponding peaks are observed for $\mathrm{PbI}_{2}$ or $\mathrm{I}_{2}$, which typically show decomposition of perovskite in the presence of humidity. The XRD spectra of PeP films stored in the dark (measured after 800, 1800, $2000 \mathrm{~h}$ for 5, 10, and $20 \mathrm{wt} \%$, respectively) show no structural variations and explain why perovskite films in the dark did not change color (Fig. $3 \mathrm{~b}, \mathrm{e}, \mathrm{h}$ and $\mathrm{k}$ ). This provides the most compelling evidence that humidity alone does not decompose perovskite films, as least notably, contrary to the widespread understanding in the literature.

On the other hand, the perovskite films when exposed to light undergo drastic structural decomposition, particularly, for pure $\mathrm{CH}_{3} \mathrm{NH}_{3} \mathrm{PbI}_{3}$ samples without any polymer matrix (Fig. 6c). The appearance of peaks corresponding to $\mathrm{PbI}_{2}$ and $\mathrm{I}_{2}$ at $2 \theta \sim 12.8^{\circ}$ and $2 \theta \sim 38.8^{\circ}$ shows vanishing of the major characteristics peaks of $\mathrm{CH}_{3} \mathrm{NH}_{3} \mathrm{PbI}_{3}$ and evidences decomposition of the perovskite crystals. This structural deformation is more intense for pure $\mathrm{CH}_{3} \mathrm{NH}_{3} \mathrm{PbI}_{3}$ and $5 \mathrm{wt} \%$ PeP films that degrade within 100 and $300 \mathrm{~h}$ and systematically reduced upon further increase in PVP concentration. The $10 \mathrm{wt} \%$ PeP films however showed that $\mathrm{PbI}_{2}$ major perovskite peaks at $2 \theta \sim 14.8$, 28.8 and $43.4^{\circ}$ are also visible even after $600 \mathrm{~h}$. Alternatively, no traces of $\mathrm{PbI}_{2}$ are found for $20 \mathrm{wt} \% \mathrm{PeP}$ films and dominant perovskite peaks are also clear although a small peak corresponding to $\mathrm{I}_{2}$ is noted after $800 \mathrm{~h}$. This explains the color of perovskite films observed in their corresponding photographs (Fig. 3c, f, i, and l).

To further validate the relative change in the crystal structure of perovskite in the dark and light, we recorded the FTIR spectra of the four representative thin films after a notable degradation is tracked using optical characterization techniques. The fresh
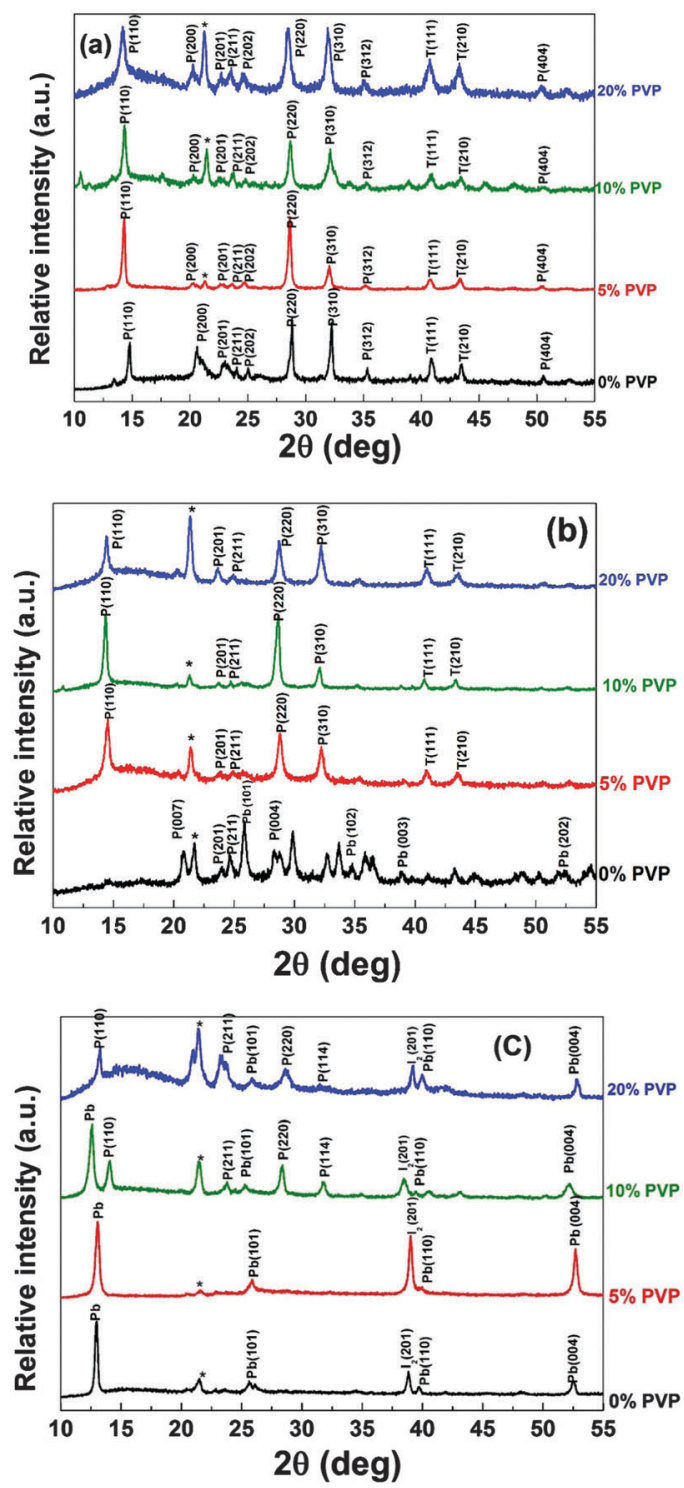

Fig. 6 XRD spectra of $\mathrm{CH}_{3} \mathrm{NH}_{3} \mathrm{Pbl}_{3}$ films with different polymer concentrations $\left(0,5,10\right.$, and 20 wt\% PVP). (a) Fresh $\mathrm{CH}_{3} \mathrm{NH}_{3} \mathrm{Pbl}$ films, (b) $\mathrm{CH}_{3} \mathrm{NH}_{3} \mathrm{Pbl}_{3}$ films kept in the dark (Rel. $\mathrm{H}>70 \%$ ) (c) $\mathrm{CH}_{3} \mathrm{NH}_{3} \mathrm{Pbl}_{3}$ films exposed to room light (Rel. $\mathrm{H}>70 \%)$.

FTIR and also the corresponding spectra of the devices after degradation in the dark are given in the ESI $\dagger$ (Fig. SI-7 and 8). Fig. 7 shows the FTIR spectra of perovskite films exposed to light. The corresponding peaks related to symmetrical and assymetrical vibrations of $\mathrm{N}-\mathrm{H}$ stretching, $\mathrm{C}-\mathrm{H}$ stretching, $\mathrm{N}-\mathrm{H}$ bending, C-N stretching and $\mathrm{C}-\mathrm{H}$ bending at 3453, 2707, 1638, 1464 , and $1383 \mathrm{~cm}^{-1}$ retained their peak position in the dark showing no structural variations; however, for the samples exposed to light the corresponding peaks related to $\mathrm{C}-\mathrm{N}$ stretching and $\mathrm{C}-\mathrm{H}$ bending disappeared for the 0 and $5 \mathrm{wt} \% \mathrm{PVP}$ incorporated films. Also, a shift in the peak position is noted for $\mathrm{C}-\mathrm{H}$ stretching from 2707 to $2844 \mathrm{~cm}^{-1}$ and for $\mathrm{C}-\mathrm{H}$ bend from 1638 to $1652 \mathrm{~cm}^{-1}$. The disappearance of peaks and the relvant peak shift evidences structural variations of perovskite crystals that could be attributed to the deformation of $\mathrm{CH}_{3} \mathrm{NH}_{3} \mathrm{PbI}_{3}$. 


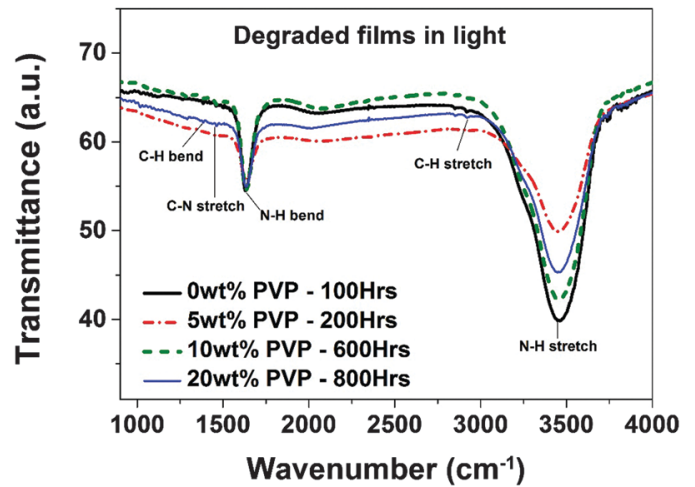

Fig. 7 FTIR spectra of the four perovskite thin films exposed to light at high humidty. The spectra are recorded after the degradation is tracked using their optical properties.

Fig. 8 shows a track of the lifetime (time taken until a notable degradation in the perovskite films is observed) of the perovskite films as a function of the PVP concentration. The polymer matrix enhanced the air stability of the PeP films by an order of magnitude when exposed to extreme stress factors; i.e., Rel. H. $>70 \%$ and room light (Rel. H. $>70 \%$ and light intensity $\sim 5 \mathrm{~mW} \mathrm{~cm}^{-2}$ ). The observation that perovskite films do not degrade significantly when exposed to humidity alone and it is rather the nature of the ETL/perovskite interface and also the surface defects of $\mathrm{TiO}_{2}$ that are triggered in the presence of light (as observed from optical and surface investigations and confirmed from FTIR and XRD) is also hinted in a few previous reports. ${ }^{35,50,67}$ Various possible reasons could lead to structural decomposition when a dual stress (humidity and light) is applied to perovskite films. Ion migration across the $\mathrm{TiO}_{2}$ /perovskite interface is one of such possibilities as also suggested in our previous reports. ${ }^{18,46}$ Given the highly volatile nature of the $\mathrm{CH}_{3} \mathrm{NH}_{3} \mathrm{I}^{+}$cation in the $\mathrm{CH}_{3} \mathrm{NH}_{3} \mathrm{PbI}_{3}$ crystal $^{68}$ such an interfacial migration will result in the formation of new Ti- $\mathrm{CH}_{3} \mathrm{NH}_{3} \mathrm{I}^{+}$complexes which may be the unidentified peaks in the XRD spectra (Fig. $6 \mathrm{~b}$ and c, marked by $\mathrm{a}^{*}$ ). Furthermore, as $\mathrm{TiO}_{2}$ is a photosensitive material, well known for its surface defects, it appears that

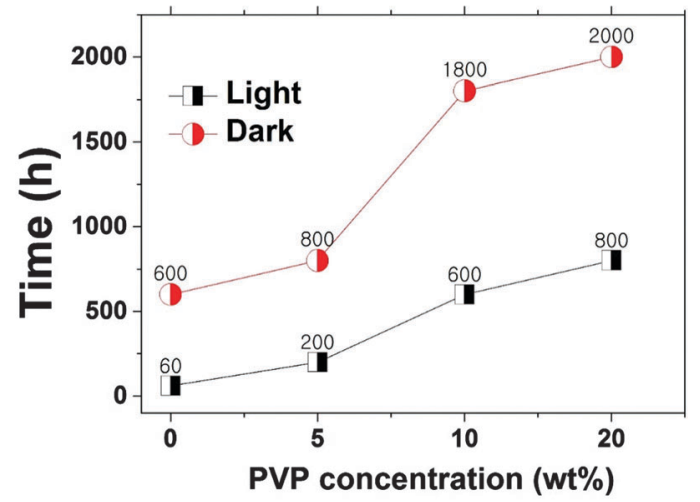

Fig. 8 Lifetime of the perovskite film as a function of PVP concentration calculated from our experiments kept in the dark and light (both under high humidity, Rel. H. > 70\%).
Table 1 Photovoltaic parameters of PSCs made using pure perovskite and PVP-perovskite films

\begin{tabular}{|c|c|c|c|c|c|c|}
\hline Device & $\begin{array}{l}P_{\mathrm{IN}} \\
\left(\mathrm{mW} \mathrm{cm}{ }^{-2}\right)\end{array}$ & $\begin{array}{l}\text { Scan } \\
\text { direction }\end{array}$ & $\begin{array}{l}J_{\mathrm{SC}} \\
\left(\mathrm{mA} \mathrm{cm}{ }^{-2}\right)\end{array}$ & $\begin{array}{l}V_{\mathrm{OC}} \\
(\mathrm{V})\end{array}$ & FF & $\begin{array}{l}\text { PCE } \\
(\%)\end{array}$ \\
\hline Pure perovskite & 80 & Forward & 12.55 & 0.58 & 0.26 & 2.34 \\
\hline film & 80 & Reverse & 11.28 & 0.69 & 0.50 & 4.91 \\
\hline Polymer-perovskite & 80 & Forward & 9.75 & 0.74 & 0.17 & 1.57 \\
\hline matrix films & 80 & Reverse & 11.02 & 0.80 & 0.33 & 3.59 \\
\hline
\end{tabular}

these surface traps are activated in the presence of light, and act as decomposition centres and films degrade due to a possible photochemical reaction. Upon incorporating $\mathrm{CH}_{3} \mathrm{NH}_{3} \mathrm{PbI}_{3}$ in a PVP matrix such an interfacial degradation could be controlled.

Finally, we also employ PeP films to fabricate a PSC and compare its performance to a reference device made using pure perovskite films (see Table 1). The details of device fabrication are in the ESI. $\uparrow$ The unoptimized PSCs resulted in a best PCE of $\sim 4.91 \%$ for a reference device whereas the PCE dropped by $\sim 27 \%$ when a $5 \mathrm{wt} \%$ PeP film is employed. The primary objective of device fabrication in this article is to examine whether or not charge injection from the PeP occurs such that the PSCs show $J_{\mathrm{SC}}$ and $V_{\mathrm{OC}}$. This test is particularly important given that PVP, embedded in the perovskite crystals, is an insulator. Promisingly, the devices using PeP showed acceptable $J_{\text {SC }}$ and $V_{\text {OC }}$ values (Table 1 ); these values are similar to the average $J_{\mathrm{SC}}$ and $V_{\mathrm{OC}}$ routinely reported in DSSCs and OSCs. Notable drawbacks of the present devices are poor fill factor (FF $<40 \%)$ and large hysteresis $(\sim 50 \%)$ - overcoming them would result in highly efficient and stable PSCs. It is important to note that a high efficiency of $\sim 16 \%$ for perovskite films embedded in a polymer (PEG) has been recently reported with high stability. ${ }^{51}$ Our future research will include optimizing the thickness of the PeP films (currently $\sim 1-1.3 \mu \mathrm{m}$ ) as well as determining the factors contributing to the lower FF and large hysteresis to improve their photovoltaic performance.

\section{Conclusions}

In conclusion, we compared the air stability of pure perovskite $\left(\mathrm{CH}_{3} \mathrm{NH}_{3} \mathrm{PbI}_{3}\right)$ thin films with those employing a polymer (polyvinylpyrrolidone, PVP)-perovskite matrix stored in the dark and in light at a high humidity of $>70 \%$. We note that even a prolonged exposure of $\mathrm{CH}_{3} \mathrm{NH}_{3} \mathrm{PbI}_{3}$ films results in minor decomposition of perovskite to its initial constituting precursors when exposed to humidity in the dark and this degradation could be completely overcome in polymer-perovskite (PeP) films. Alternatively, when exposed to light, the films showed $\sim 10$ times faster degradation in the presence of humidity, the extent of which was inversely proportional to increasing polymer concentration, suggesting photodegradation to be the dominant stress factor. Based on detailed surface, optical and chemical characterization of the pure perovskite films and their PeP counterparts in the dark and light, we conclude that degradation is caused due to native surface defects of $\mathrm{TiO}_{2}$, which are activated in light and result in an imbalance of 
charges in the perovskite crystals. Also, the surface traps act as humidity sites resulting in the decomposition of $\mathrm{CH}_{3} \mathrm{NH}_{3} \mathrm{PbI}_{3}$ to $\mathrm{CH}_{3} \mathrm{NH}_{3} \mathrm{I}, \mathrm{PbI}_{2}$ and $\mathrm{I}_{2}$. Furthermore, we control the reactivity of the $\mathrm{TiO}_{2} /$ perovskite interface via incorporating a polymer matrix which avoided ion migration across the interface. Our results can support ambient processing of high quality and air-stable perovskite films without the need for an inert environment and can be applied to mass production compatible fabrication of perovskite solar cells. The perovskite solar cells fabricated using the polymer embedded perovskite films confirm that charge injection occurs from this composite and results in an appreciable current $\left.(\sim 11 \mathrm{~mA} \mathrm{~cm})^{-2}\right)$ and voltage $(0.80 \mathrm{~V})$. However, the fill factor of the devices was $<40 \%$ and showed a hysteresis of $\sim 50 \%$ - eliminating these drawbacks would result in stable and efficient perovskite solar cells.

\section{Acknowledgements}

The authors acknowledge financial support from the Ministry of Higher Education Malaysia (MOHE) under grant FRGS 140126. A. F. acknowledges the Alexander von Humboldt Foundation for a postdoctoral fellowship.

\section{References}

1 A. Kojima, et al., Organometal Halide Perovskites as VisibleLight Sensitizers for Photovoltaic Cells, J. Am. Chem. Soc., 2009, 131(17), 6050-6051.

2 M. Saliba, et al., Cesium-containing triple cation perovskite solar cells: improved stability, reproducibility and high efficiency, Energy Environ. Sci., 2016, 9, 1989-1997.

3 W. S. Yang, et al., High-performance photovoltaic perovskite layers fabricated through intramolecular exchange, Science, 2015, 348((6240)), 1234-1237.

4 D. Bi, et al., Efficient luminescent solar cells based on tailored mixed-cation perovskites, Sci. Adv., 2016, 2(1), e1501170.

5 M. Saliba, et al., A molecularly engineered hole-transporting material for efficient perovskite solar cells, Nat. Energy, 2016, 15017.

6 S. De Wolf, et al., Organometallic halide perovskites: Sharp optical absorption edge and its relation to photovoltaic performance, J. Phys. Chem. Lett., 2014, 5(6), 1035-1039.

7 S. D. Stranks, et al., Electron-hole diffusion lengths exceeding 1 micrometer in an organometal trihalide perovskite absorber, Science, 2013, 342(6156), 341-344.

8 G. Xing, et al., Long-range balanced electron-and holetransport lengths in organic-inorganic $\mathrm{CH}_{3} \mathrm{NH}_{3} \mathrm{PbI}_{3}$, Science, 2013, 342(6156), 344-347.

9 H. S. Kim, et al., Lead iodide perovskite sensitized all-solidstate submicron thin film mesoscopic solar cell with efficiency exceeding 9\%, Sci. Rep., 2012, 2, 591.

10 C. C. Stoumpos, C. D. Malliakas and M. G. Kanatzidis, Semiconducting tin and lead iodide perovskites with organic cations: phase transitions, high mobilities, and nearinfrared photoluminescent properties, Inorg. Chem., 2013, 52, 9019-9038.
11 Q. Dong, et al., Electron-hole diffusion lengths $>175 \mathrm{~m}$ in solution grown $\mathrm{CH}_{3} \mathrm{NH}_{3} \mathrm{PbI}_{3}$ single crystals, Science, 2015, 347, 967-970.

12 A. Fakharuddin, et al., Channeling of electron transport to improve collection efficiency in mesoporous titanium dioxide dye sensitized solar cell stacks, Appl. Phys. Lett., 2014, 104, 053905.

13 Q. Wali, A. Fakharuddin and R. Jose, Tin oxide as a photoanode for dye-sensitised solar cells: Current progress and future challenges, J. Power Sources, 2015, 293, 1039-1052.

$14 \mathrm{H}$. Zhou, et al., Interface engineering of highly efficient perovskite solar cells, Science, 2014, 345(6196), 542-546.

15 C. Bi, et al., Non-wetting surface-driven high-aspect-ratio crystalline grain growth for efficient hybrid perovskite solar cells, Nat. Commun., 2015, 6, 7747.

$16 \mathrm{~W}$. Qiu, et al., Pinhole-free perovskite films for efficient solar modules, Energy Environ. Sci., 2016, 9(2), 484-489.

17 F. Matteocci, et al., High efficiency photovoltaic module based on mesoscopic organometal halide perovskite, Prog. Photovoltaics, 2016, 24(4), 436-445.

18 A. Fakharuddin, et al., Vertical $\mathrm{TiO}_{2}$ Nanorods as a Medium for Stable and High-Efficiency Perovskite Solar Modules, ACS Nano, 2015, 9(8), 8420-8429.

19 A. Fakharuddin, et al., Solid state perovskite solar modules by vacuum-vapor assisted sequential deposition on $\mathrm{Nd}: \mathrm{YVO}_{4}$ laser patterned rutile $\mathrm{TiO}_{2}$ nanorods, Nanotechnology, 2015, 26(49), 494002.

$20 \mathrm{~J}$. H. Heo, et al., Highly efficient low temperature solution processable planar type $\mathrm{CH}_{3} \mathrm{NH}_{3} \mathrm{PbI}_{3}$ perovskite flexible solar cells, J. Mater. Chem. A, 2016, 4(5), 1572-1578.

21 F. Di Giacomo, et al., Flexible perovskite photovoltaic modules and solar cells based on atomic layer deposited compact layers and UV-irradiated $\mathrm{TiO}_{2}$ scaffolds on plastic substrates, Adv. Energy Mater., 2015, 5(8), 1401808.

22 C.-Y. Chen, et al., Perovskite Photovoltaics for Dim-Light Applications, Adv. Funct. Mater., 2015, 25(45), 7064-7070.

23 L. K. Ono, et al., Fabrication of semi-transparent perovskite films with centimeter-scale superior uniformity by the hybrid deposition method, Energy Environ. Sci., 2014, 7(12), 3989-3993.

24 L. Bu, et al., Semitransparent Fully Air Processed Perovskite Solar Cells, ACS Appl. Mater. Interfaces, 2015, 7(32), 17776-17781.

25 E. Della Gaspera, et al., Ultra-thin high efficiency semitransparent perovskite solar cells, Nano Energy, 2015, 13, 249-257.

26 N. Espinosa, et al., Solution and vapour deposited lead perovskite solar cells: Ecotoxicity from a life cycle assessment perspective, Sol. Energy Mater. Sol. Cells, 2015, 137, 303-310.

27 J. Gong, S. B. Darling and F. You, Perovskite photovoltaics: Life-cycle assessment of energy and environmental impacts, Energy Environ. Sci., 2015, 8(7), 1953-1968.

28 B. E. Hardin, H. J. Snaith and M. D. McGehee, The renaissance of dye-sensitized solar cells, Nat. Photonics, 2012, 6(3), 162-169.

29 Z. M. Beiley and M. D. McGehee, Modeling low cost hybrid tandem photovoltaics with the potential for efficiencies exceeding 20\%, Energy Environ. Sci., 2012, 5(11), 9173-9179. 
30 A. Fakharuddin, et al., A perspective on the production of dye-sensitized solar modules, Energy Environ. Sci., 2014, $7(12), 3952-3981$.

31 T. A. Berhe, et al., Organometal Halide Perovskite Solar Cells: Degradation and Stability, Energy Environ. Sci., 2016, 9, 323-356.

32 T. Leijtens, et al., Stability of metal halide perovskite solar cells, Adv. Energy Mater., 2015, 5(20), 1500963.

33 D. Wang, et al., Stability of perovskite solar cells, Sol. Energy Mater. Sol. Cells, 2016, 147, 255-275.

34 G. Murugadoss, et al., Light stability tests of methylammonium and formamidinium Pb-halide perovskites for solar cell applications, Jpn. J. Appl. Phys., 2015, 54(8), 08KF08.

35 J. A. Christians, P. A. Miranda Herrera and P. V. Kamat, Transformation of the Excited State and Photovoltaic Efficiency of $\mathrm{CH}_{3} \mathrm{NH}_{3} \mathrm{PbI}_{3}$ Perovskite upon Controlled Exposure to Humidified Air, J. Am. Chem. Soc., 2015, 137(4), 1530-1538.

$36 \mathrm{Y}$. Zhao and $\mathrm{K}$. Zhu, Optical bleaching of perovskite $\left(\mathrm{CH}_{3} \mathrm{NH}_{3}\right)$ $\mathrm{PbI}_{3}$ through room-temperature phase transformation induced by ammonia, Chem. Commun., 2014, 50(13), 1605-1607.

37 L. Zheng, et al., A hydrophobic hole transporting oligothiophene for planar perovskite solar cells with improved stability, Chem. Commun., 2014, 50(76), 11196-11199.

38 J. Yang, et al., Investigation of $\mathrm{CH}_{3} \mathrm{NH}_{3} \mathrm{PbI}_{3}$ Degradation Rates and Mechanisms in Controlled Humidity Environments Using in Situ Techniques, ACS Nano, 2015, 9(2), 1955-1963.

39 N. Aristidou, et al., The Role of Oxygen in the Degradation of Methylammonium Lead Trihalide Perovskite Photoactive Layers, Angew. Chem., Int. Ed., 2015, 54(28), 8208-8212.

40 M. K. Gangishetty, R. W. J. Scott and T. L. Kelly, Effect of relative humidity on crystal growth, device performance and hysteresis in planar heterojunction perovskite solar cells, Nanoscale, 2016, 8, 6300-6307.

41 G. E. Eperon, et al., The Importance of Moisture in Hybrid Lead Halide Perovskite Thin Film Fabrication, ACS Nano, 2015, 9(9), 9380-9393.

$42 \mathrm{~J}$. Yang, et al., Investigation of $\mathrm{CH}_{3} \mathrm{NH}_{3} \mathrm{PbI}_{3}$ degradation rates and mechanisms in controlled humidity environments using in situ techniques, ACS Nano, 2015, 9(2), 1955-1963.

$43 \mathrm{~J}$. M. Frost, et al., Atomistic origins of high-performance in hybrid halide perovskite solar cells, Nano Lett., 2014, 14(5), 2584-2590.

44 T. Leijtens, et al., Overcoming ultraviolet light instability of sensitized $\mathrm{TiO}_{2}$ with meso-superstructured organometal tri-halide perovskite solar cells, Nat. Commun., 2013, 4, 2885.

45 H. C. Weerasinghe, et al., Encapsulation for improving the lifetime of flexible perovskite solar cells, Nano Energy, 2015, 18, 118-125.

46 A. Fakharuddin, et al., Role of morphology and crystallinity of nanorod and planar electron transport layers on the performance and long term durability of perovskite solar cells, J. Power Sources, 2015, 283, 61-67.

47 I. Hwang, M. Baek and K. Yong, Core/Shell Structured $\mathrm{TiO}_{2} / \mathrm{CdS}$ Electrode to Enhance the Light Stability of Perovskite Solar Cells, ACS Appl. Mater. Interfaces, 2015, 7(50), 27863-27870.

$48 \mathrm{~S}$. Ito, et al., Effects of surface blocking layer of $\mathrm{Sb}_{2} \mathrm{~S}_{3}$ on nanocrystalline $\mathrm{TiO}_{2}$ for $\mathrm{CH}_{3} \mathrm{NH}_{3} \mathrm{PbI}_{3}$ perovskite solar cells, J. Phys. Chem. C, 2014, 118(30), 16995-17000.
49 W. Li, et al., Enhanced UV-light stability of planar heterojunction perovskite solar cells with caesium bromide interface modification, Energy Environ. Sci., 2016, 9(2), 490-498.

50 F. Matsumoto, et al., Photodecomposition and Morphology Evolution of Organometal Halide Perovskite Solar Cells, J. Phys. Chem. C, 2015, 119(36), 20810-20816.

51 Y. Zhao, et al., A polymer scaffold for self-healing perovskite solar cells, Nat. Commun., 2016, 7, 10228.

52 M. O. Reese, et al., Consensus stability testing protocols for organic photovoltaic materials and devices, Sol. Energy Mater. Sol. Cells, 2011, 95(5), 1253-1267.

53 R. Roesch, et al., Procedures and practices for evaluating thinfilm solar cell stability, Adv. Energy Mater., 2015, 5(20), 1501407.

54 M. Jørgensen, et al., Stability of Polymer Solar Cells, Adv. Mater., 2012, 24(5), 580-612.

$55 \mathrm{~J}$. You, et al., Moisture assisted perovskite film growth for high performance solar cells, Appl. Phys. Lett., 2014, 105(18), 183902.

56 J. Even, L. Pedesseau and C. Katan, Theoretical insights into multibandgap hybrid perovskites for photovoltaic applications, SPIE-Int. Soc. Opt. Eng., Proc., 2014, 91400Y.

57 A. Sadhanala, et al., Blue-Green colour tuneable solution processable organolead chloride-bromide mixed halide perovskites for optoelectronic applications, Nano Lett., 2015, 15(9), 6095-6101.

58 S. A. Bretschneider, et al., Research update: Physical and electrical characteristics of lead halide perovskites for solar cell applications, APL Mater., 2014, 2(4), 040701.

59 K. G. Stamplecoskie, J. S. Manser and P. V. Kamat, Dual nature of the excited state in organic-inorganic lead halide perovskites, Energy Environ. Sci., 2015, 8(1), 208-215.

$60 \mathrm{~J}$. Xiong, et al., Interface degradation of perovskite solar cells and its modification using an annealing-free $\mathrm{TiO}_{2} \mathrm{NPs}$ layer, Org. Electron., 2016, 30, 30-35.

$61 \mathrm{~J}$. Hyuck Heo, et al., Hysteresis-less mesoscopic $\mathrm{CH}_{3} \mathrm{NH}_{3} \mathrm{PbI}_{3}$ perovskite Hybrid solar cells by introduction of Li-treated $\mathrm{TiO}_{2}$ electrode, Nano Energy, 2015, 15, 530-539.

62 M. De Bastiani, et al., Role of the crystallization substrate on the photoluminescence properties of organo-lead mixed halides perovskites, APL Mater., 2014, 2(8), 081509.

63 S. Rein, Lifetime Spectroscopy: A Method of Defect Characterization in Silicon for Photovoltaic Applications, Springer, 2004.

64 F. Hao, et al., Lead-free solid-state organic-inorganic halide perovskite solar cells, Nat. Photonics, 2014, 8(6), 489-494.

65 Y. Yamada, et al., Photocarrier Recombination Dynamics in Perovskite $\mathrm{CH}_{3} \mathrm{NH}_{3} \mathrm{PbI}_{3}$ for Solar Cell Applications, J. Am. Chem. Soc., 2014, 136(33), 11610-11613.

66 G. Niu, X. Guo and L. Wang, Review of recent progress in chemical stability of perovskite solar cells, J. Mater. Chem. A, 2015, 3(17), 8970-8980.

67 M. Govindhasamy, et al., Light stability tests of methylammonium and formamidinium $\mathrm{Pb}$-halide perovskites for solar cell applications, Jpn. J. Appl. Phys., 2015, 54(8S1), 08KF08.

68 T. A. Berhe, et al., Organometal halide perovskite solar cells: degradation and stability, Energy Environ. Sci., 2016, 9(2), 323-356. 